Relations industrielles

Industrial Relations

\title{
Les relations publiques, Pourquoi? Comment? Par Bernard Lecoq, Paris, Collection Cadreco, Entreprise Moderne d'Édition, 1970, 108 pp.
}

\section{Gaétan Hubert}

Volume 27, numéro 4, 1972

URI : https://id.erudit.org/iderudit/028356ar

DOI : https://doi.org/10.7202/028356ar

Aller au sommaire du numéro

\section{Éditeur(s)}

Département des relations industrielles de l'Université Laval

\section{ISSN}

0034-379X (imprimé)

1703-8138 (numérique)

Découvrir la revue

Citer ce compte rendu

Hubert, G. (1972). Compte rendu de [Les relations publiques, Pourquoi? Comment? Par Bernard Lecoq, Paris, Collection Cadreco, Entreprise Moderne d'Édition, 1970, 108 pp.] Relations industrielles / Industrial Relations, 27(4), 801-801. https://doi.org/10.7202/028356ar

Tous droits réservés (C) Département des relations industrielles de l'Université Laval, 1972
Ce document est protégé par la loi sur le droit d'auteur. L'utilisation des services d’Érudit (y compris la reproduction) est assujettie à sa politique d'utilisation que vous pouvez consulter en ligne.

https://apropos.erudit.org/fr/usagers/politique-dutilisation/ 
Les relations publiques, Pourquoi ? Comment ?, par Bernard Lecoq, Paris, Collection Cadreco, Entreprise moderne d'édition, 1970, 108 pp.

Cet ouvrage présenté à l'Entreprise moderne d'édition en format de poche est accessible à tous ceux qui œuvrent dans une organisation quelle qu'elle soit. L'auteur se propose de nous démontrer que les relations publiques sont nécessaires au bon fonctionnement d'un groupe, qu'il s'agisse d'une entreprise, d'une école, d'une municipalité ou même d'un Etat et qu'elles sont à la portée de tous. Il veut recréer les rapports humains spontanés, autant à l'intérieur qu'à l'extérieur de l'organisation.

L'auteur prétend que son volume s'adresse aux cadres supérieurs de l'entreprise alors que selon nous, il s'adresse davantage aux niveaux inférieurs de cadre dans le contexte de l'entreprise nordaméricaine.

Il s'agit en premier lieu d'un réaménagement simplifié des données américaines sur ce sujet et en deuxième lieu, d'une énumération des moyens, toujours américains, pour arriver à projeter une image favorable de l'entreprise tant auprès des employés qu'auprès du grand public.

L'ouvrage peut présenter un certain intérêt pour des gens qui ont peu de connaissance ou d'expérience dans le domaine des relations publiques mais il se fait beaucoup mieux et surtout plus adapté à notre contexte chez nos voisins du sud, quoi qu'on en dise.

\section{Gaétan HUBERT}

Effective Management by Objectives, by W. J. Reddin, Scarborough, Ontario, McGraw-Hill Ryerson Ltd., 1971, 224 pp.

Prenant pour acquis les éléments théoriques de la Direction Par les Objectifs (D.P.O) largement diffusés depuis Peter Drucker par George Odiorne et John Humble, W. J. Reddin plonge dans la pratique de ce style de direction. Dans une approche essentiellement orientée vers l'action de tous les jours, il livre la D.P.O. à l'administrateur en tant qu'individu, comblant ainsi une importante lacune de la littérature sur le sujet.

L'ouvrage tente d'apporter une double contribution. La première réside dans l'élaboration du concept d'efficacité administrative que l'auteur avait introduit dans son précédent ouvrage: Managerial
Effectiveness. L'efficacité du dirigeant voire de l'organisation procède par une description adéquate de la position, de la tâche en termes de résultats à atteindre («outputs») et non d'activités («inputs»). Abondamment illustrés d'exemples pratiques, les deux premiers tiers du volume s'emploient ainsi à développer des concepts tels les zones et les standards d'efficacité, à expliciter la façon de déterminer ces «exigences générales $\gg$ d'une tâche et les objectifs correspondants. L'élaboration d'un plan de réalisation des objectifs et la mesure de la performance accomplie s'inscrivent également dans ces préoccupations.

La seconde contribution de l'ouvrage, ce sont les techniques d'une solide implantation de la D.P.O. dans une organisation dont l'équipe d'implantation, cette unité qui a pour but de faciliter le changement, constitue l'un des éléments-clés. De nombreuses tentatives d'implantation de la D.P.O. ont échoué parce qu'on avait négligé l'aspect «changement qu'elle implique. Une phase de dégel adéquate, l'acceptation de la dimension humaine, la nécessité d'une action d'équipe, un taux de changement approprié et l'engagement total de la haute direction sont autant d'éléments à considérer quand il s'agit de modifier le style de direction dans une organisation. Dans les derniers chapitres Reddin s'attarde donc à de telles considérations pour présenter en guise de conclusion les bénéfices que peuvent retirer d'une direction efficace par les objectifs tant les dirigeants et leurs subordonnés que l'organisation elle-même.

En publiant Effective Management by Objectives, W. J. Reddin marque sans aucun doute un pas en avant dans la littérature sur la Direction Par les Objectifs. Complément indispensable du livre de George Odiorne (à noter qu'il est souhaitable d'avoir lu Management by Objectives par Odiorne auparavant !), cet ouvrage saurait profiter à tout administrateur même si celui-ci n'envisage pas d'introduire la D.P.O. dans son entreprise. Le concept d'efficacité et le processus de détermination des objectifs qui y sont présentés, constituent en effet des éléments susceptibles d'améliorer le rendement de quiconque tout en augmentant l'intérêt de celui qui cherche à mieux définir et mesurer ses réalisations.

Jean-Louis LANGEVIN 